\title{
Effect of liquid-liquid transition on solidification and wettability of $\mathrm{Sn}-0.7 \mathrm{Cu}-x \mathrm{Bi}$ solder
}

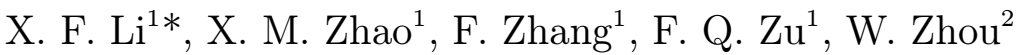 \\ ${ }^{1}$ School of Materials Science and Engineering, Hefei University of Technology, Hefei 230009, P. R. China \\ ${ }^{2}$ School of Mechanical and Aerospace Engineering, Nanyang Technological University, Singapore 39798, Singapore
}

Received 5 December 2014, received in revised form 9 January 2015, accepted 19 January 2015

\begin{abstract}
The electrical resistivity-temperature curve $(\rho-T)$ of $\mathrm{Sn}-0.7 \mathrm{Cu}-x \mathrm{Bi}($ wt. $\%)$ melts was measured, and anomalous changes were observed on the $\rho-T$ curve at the temperature far above the corresponding liquidus. The results reveal that the melts have experienced a temperatureinduced liquid-liquid transition (LLT), and the transition is reversible after the first cycle heating. Based on the result of LLT, solidification experiments and spreadability testing were carried out on the $\mathrm{Sn}-0.7 \mathrm{Cu}-x \mathrm{Bi}$ alloy to investigate the effect of LLT on the solidification and wettability. The results show that the microstructure was refined, and the wettability was improved when the solder samples solidified from the melt experienced LLT.
\end{abstract}

K e y w o r d s: Sn-0.7Cu- $x$ Bi solders, liquid-liquid transition, solidification, wettability

\section{Introduction}

The nature of liquid structures and properties remains an open problem for understanding many fundamental and applied fields such as materials science and processing. It is widely believed that a liquid state has a great effect on the microstructures and properties of as-cast materials. Melt thermal treatment and melt superheating treatment have been widely explored and used in modifying the solidification microstructure and improving the mechanical or physical properties of various materials: metallic alloys [1-3], aerogel [4], and polyethylene [5]. But the exact mechanism is still not fully understood, and there are discrepancies in the explanations put forward $[6]$.

In recent years, the liquid-liquid transition has attracted much attention in liquid physics and materials field. Many experimental and theoretical studies have shown that temperature- or pressure-induced liquidliquid transition can exist in some single-component and multicomponent liquids [7-12]. In our previous study, temperature induced liquid-liquid transitions (LLTs) have been observed in some binary alloys, such as In-Sn, In-Bi, Pb-Sn, Cu-Sn, and $\mathrm{Pb}-\mathrm{Bi}$, by the electrical resistivity method [13-15], X-ray diffraction $[16,17]$, revised internal friction method [18], and differential scanning calorimetry (DSC) [19]. Compared with other experiments, electrical resistivity experiment is a relatively effective method to investigate liquid-liquid changes.

Because of the hazard of lead on the environment and human health in the field of solders, it has been extensively accepted that lead-free solders should substitute the traditional $\mathrm{Sn}-\mathrm{Pb}$ solders. Among the Sn-base lead-free solders such as Sn-Ag, Sn-Cu, Sn-Ag-Cu, $\mathrm{Sn}-\mathrm{Zn}$, and $\mathrm{Sn}-\mathrm{Bi}$ alloys, $\mathrm{Sn}-0.7 \mathrm{Cu}$ alloy system has been recognized as one of the leading candidates due to its low cost $[20,21]$. Thus, it is useful to explore the effect of melt structural transition on the solidification and properties of $\mathrm{Sn}-0.7 \mathrm{Cu}-x \mathrm{Bi}$ alloy.

In this paper, the temperature dependence of electrical resistivity on the liquid $\mathrm{Sn}-0.7 \mathrm{Cu}-x \mathrm{Bi}$ alloy was investigated, and the results suggest that a reversible structural change occurs in a relatively hightemperature range. The effect of LLT on the solidification microstructure and wettability was also discussed, which would lead to a better understanding of the nature of LLT and its effect on solidification and wettability. 


\section{Experimental procedures}

\subsection{Electrical resistivity measurements}

The electrical resistivity measurements were carried out using DC four-probe technology. The details of the measuring method are the same as described elsewhere [15]. The $\mathrm{Sn}-0.7 \mathrm{Cu}-x \mathrm{Bi}$ (wt.\%) sample was prepared with $\mathrm{Sn}, \mathrm{Cu}$, and $\mathrm{Bi}$ granules of high purity $(4 \mathrm{~N})$. The melt was heated to $500^{\circ} \mathrm{C}$, and held for $1 \mathrm{~h}$ covered with $\mathrm{KCl}-\mathrm{LiCl}$ melts, then poured into a quartz cells and cooled to a temperature below liquidus for the following experiments. During the entire melting process, the sample was agitated mechanically three times for component homogenization. In the resistivity measurements, the heating and cooling rate was both $5^{\circ} \mathrm{C} \min ^{-1}$ and the $\rho$ - $T$ curves were recorded by a computer datum collection system. The thermal expansion of the quartz was so small that the size variation with temperature could be neglected. Figure 1 shows the results of electrical resistivity measurements.

\subsection{Solidification experiments}

The melting and holding temperatures of the alloys are chosen according to the $\rho$ - $T$ curve shown in Fig. 1. Also, the overheating treatments of the liquid alloys were conducted according to the following sequential scheme: two same weight $\mathrm{Sn}-0.7 \mathrm{Cu}-x \mathrm{Bi}$ samples $\mathrm{A}$ and B $(20,000 \mathrm{~g})$ were heated and held at $500^{\circ} \mathrm{C}$ for $1 \mathrm{~h}$ covered with $\mathrm{B}_{2} \mathrm{O}_{3}$ (to avoid the evaporation and oxidation), and then cooled down. For $\mathrm{Sn}-0.7 \mathrm{Cu}$ as an example (Fig. 2), sample A was then heated to $720^{\circ} \mathrm{C}$ (before the liquid change temperature of the first heating cycle) and held for $15 \mathrm{~min}$, and then poured into an iron mold. Sample B was heated to $1100^{\circ} \mathrm{C}$ (above the temperature range with the anomalous change) and held for $15 \mathrm{~min}$, and then rapidly cooled to $720^{\circ} \mathrm{C}$. At $720^{\circ} \mathrm{C}$, it was held for another $10 \mathrm{~min}$ and finally poured into the same iron mold. The other $\mathrm{Sn}-0.7 \mathrm{Cu}-$ $-x$ Bi melts overheating temperatures are listed in Table 1 with the similarly prepared procedure.

The solidified sample was divided into two parts: one was used to analyze the microstructures; the other was used for wettability tests. The specimens for microstructures were prepared by standard metallographic procedures with an etchant of $\mathrm{FeCl}_{3}+\mathrm{HCl}+\mathrm{H}_{2} \mathrm{O}$ and observed under an optical microscope (OM).

\subsection{Wettability tests}

To evaluate the effect of LLT on wettability, spreadability tests were carried out. According to the National Standard of China GB/T 11364-2008 "Testing Method of Wettability for Brazing Filler Metals",
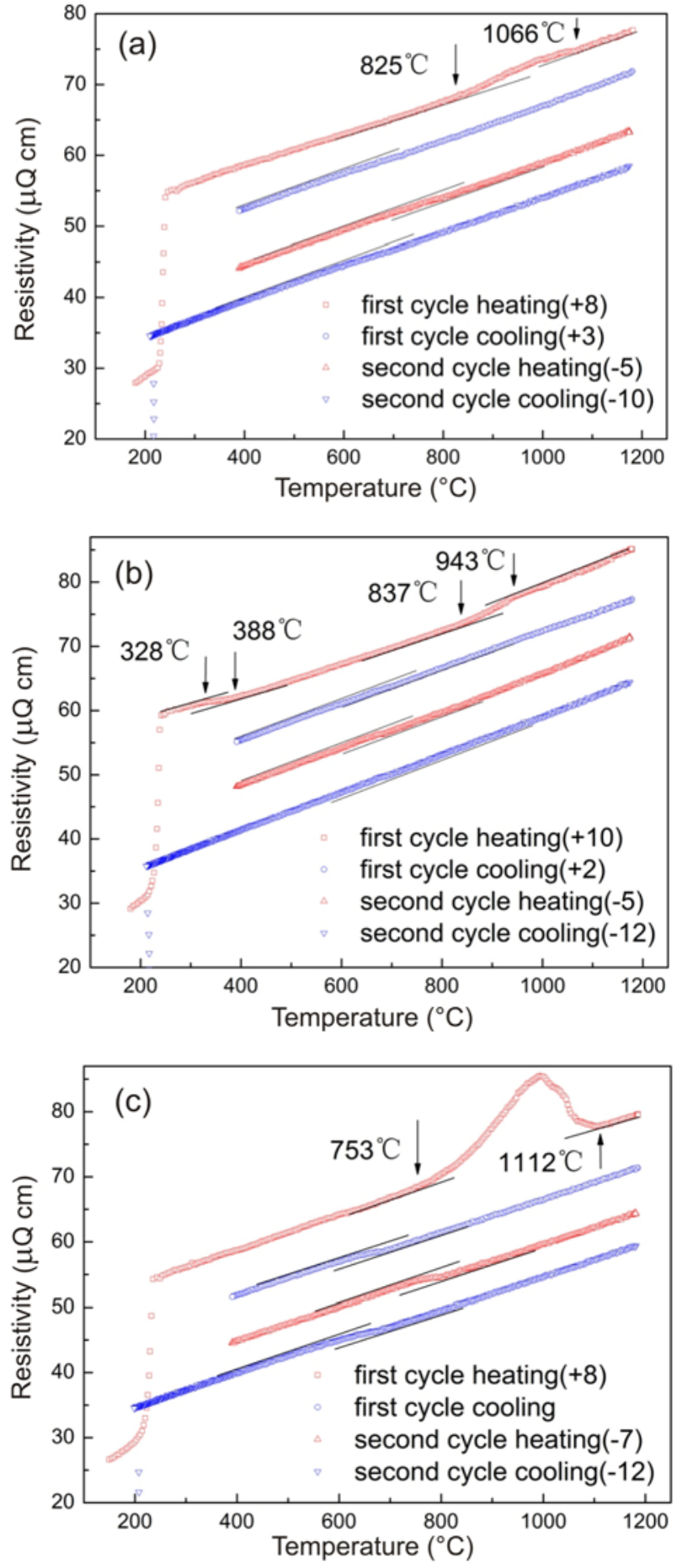

Fig. 1. Electrical resistivity-temperature curves of Sn$-0.7 \mathrm{Cu}-x \mathrm{Bi}$ alloy in two heating and cooling cycles: (a) Sn$-0.7 \mathrm{Cu}$, (b) Sn-0.7Cu-3Bi, (c) Sn-0.7Cu-5Bi. (Note: To observe the $\rho-T$ curves in different cycles, the ordinate value $\rho$ is added with a different value as listed in the inset brackets).

the substrate used was copper with a purity of 99.97 wt.\%, which was cut into the size $40 \mathrm{~mm} \times 40 \mathrm{~mm} \times$ $2 \mathrm{~mm}$. The $\mathrm{Cu}$ substrate was polished with 600 -grit 
Table 1 . The overheating temperature of $\mathrm{Sn}-0.7 \mathrm{Cu}-x \mathrm{Bi}$ alloys

\begin{tabular}{lcc}
\hline Alloy & $T_{1}\left({ }^{\circ} \mathrm{C}\right)$ & $T_{2}\left({ }^{\circ} \mathrm{C}\right)$ \\
\hline Sn-0.7Cu & 720 & 1100 \\
Sn-0.7Cu-3Bi & 730 & 1050 \\
Sn-0.7Cu-5Bi & 710 & 1150 \\
\hline
\end{tabular}

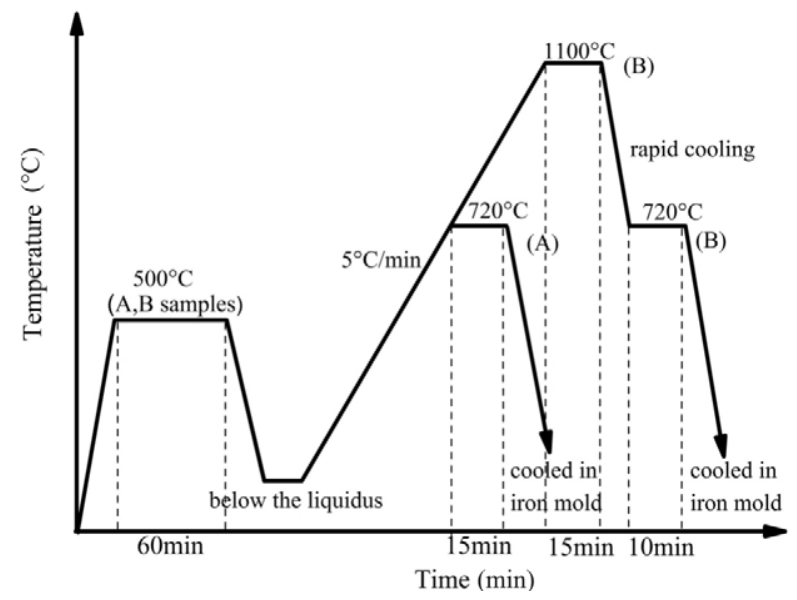

Fig. 2. Sketch of preparation procedure of liquid $\mathrm{Sn}-0.7 \mathrm{Cu}$ alloys.

sandpaper before cleaning with ethanol. The solder wafer was cut into $0.2 \pm 0.0002 \mathrm{~g}$ (using an electronic balance) with the same diameter. Spreadability tests were conducted at $260{ }^{\circ} \mathrm{C}$ with a dwelling time of $60 \mathrm{~s}$ in a resistance furnace and activated rosin was used as a flux. Spreading areas of the solders on $\mathrm{Cu}$ surface were measured.

\section{Results and discussion}

\subsection{Electrical resistivity}

From the $\rho$ - $T$ curves of the $\mathrm{Sn}-0.7 \mathrm{Cu}-x \mathrm{Bi}$ melts in Fig. 1, the melt resistivity usually increases linearly with a temperature rising above the liquidus (except for $\mathrm{Sn}-0.7 \mathrm{Cu}-3 \mathrm{Bi}$ with another low-temperature liquid change); however, they change obviously at the temperature far above their liquidus; then increases linearly again. The anomalous changes are reversible in subsequent cooling and heating process, but the turning points and the change trend are different from that of the first cycle heating. It is presumed that two types of LLT exist in $\mathrm{Sn}-0.7 \mathrm{Cu}-x \mathrm{Bi}$ melt, i.e. irreversible LLT in the first cycle heating and reversible after the first cycle heating.
It is generally accepted that the atomic bonds of crystals are only partly broken on melting, and the liquid structures are mainly composed of atomic clusters and some free atoms [22, 23]. According to [24], high-temperature X-ray diffractometer had been used to study the liquid structure of $\mathrm{Sn}-0.7 \mathrm{Cu}$ alloy, and the experimental result showed that short-range orders (SROs) were detected in the molten $\mathrm{Sn}-0.7 \mathrm{Cu}$ alloy at 260,330 , and $400^{\circ} \mathrm{C}$. Also, investigations of the high-temperature properties and SROs of melts showed that the microheterogeneous states were metastable or nonequilibrium rather than thermodynamically stable [25]. Accordingly, in this study, we can reasonably guess that there are probably many metastable SROs (such as Sn-Sn, Cu-Cu, Bi-Bi and Sn-Cu, Sn-Bi SROs) in the melt at a low temperature above the liquidus. With the temperature rising, those metastable SROs dissolve or break into stable SROs within the anomalous temperature range. Then the melt becomes more uniform and disordered. This metastable to stable transition in the $\mathrm{Sn}-0.7 \mathrm{Cu}-x \mathrm{Bi}$ melt is irreversible.

Based on the different characteristic of the anomaly on $\rho-T$ curves between the first heating cycle and the subsequent cycles, we can assume that the stable $\mathrm{Sn}-0.7 \mathrm{Cu}-x \mathrm{Bi}$ melt has some SROs with reversible change character, i.e. they can reassemble on cooling and break again on heating in the transition temperature range. According to [26], the liquid structure of Sn has been investigated by neutron scattering experiments. The experimental results showed that an obvious shoulder exists on the high-Q side of the first peak of $\mathrm{S}(\mathrm{Q})$ at 300,500 , and even $1600^{\circ} \mathrm{C}$. Since the shoulder is a sign of a covalent bond, these features for liquid Sn suggest that some tetrahedral SROs with covalent characteristics may remain in liquid Sn at lower temperatures, and at least the fragments of the tetrahedral unit could persist at high temperatures in liquid Sn. Also, comparing the results of [24] with that of the liquid structure of Sn in [27], it can be inferred that the liquid structure of $\mathrm{Sn}-0.7 \mathrm{Cu}-x \mathrm{Bi}$ solder is similar to that of $\mathrm{Sn}$ in a low-temperature range above liquidus. It is reasonable to presume that the tetrahedral SROs with the covalent characteristic in liquid $\mathrm{Sn}$ and $\mathrm{Sn}-0.7 \mathrm{Cu}-x \mathrm{Bi}$ melt may be the main cause of the reversible LLT. Moreover, it can be observed from Fig. 1 that the reversible change becomes more obvious with Bi's increasing, that is to say, the addition of $\mathrm{Bi}$ enhances the trend of reversible transition.

\subsection{Solidification microstructure}

The microstructure of samples A and B for different composition is shown in Fig. 3. According to [28], only $\beta$-Sn and $\mathrm{Cu}_{6} \mathrm{Sn}_{5}$ phases exist in the solidified $\mathrm{Sn}-0.7 \mathrm{Cu}$ alloy. From the observation of microstructure, the microstructure of the rapidly cooled 

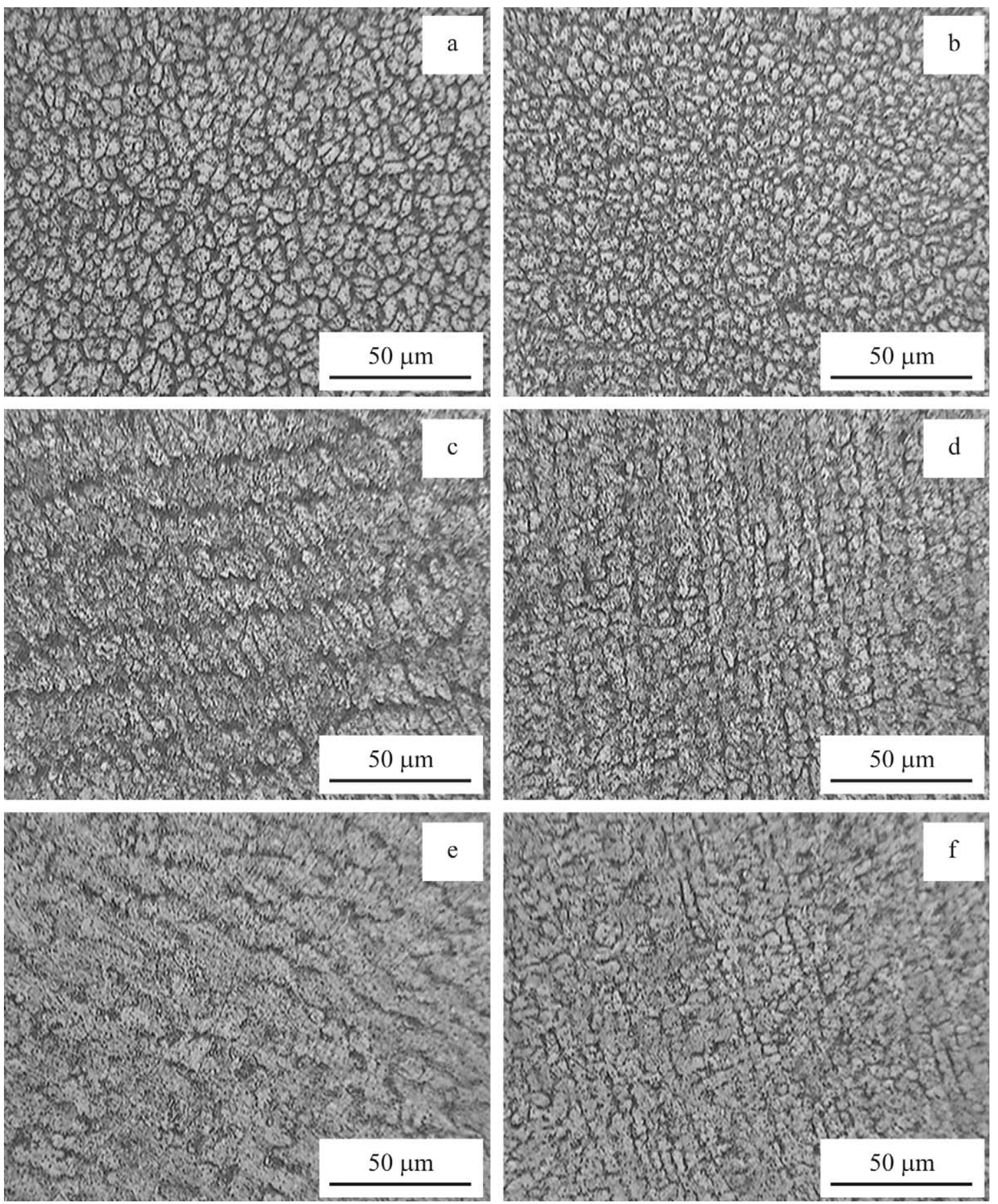

Fig. 3. Solidification microstructures of $\mathrm{Sn}-0.7 \mathrm{Cu}-x \mathrm{Bi}$ alloy in steel mold from different melt state: (a) Sn- $0.7 \mathrm{Cu}$ before LLT, (b) Sn-0.7Cu after LLT, (c) Sn-0.7Cu-3Bi before LLT, (d) Sn-0.7Cu-3Bi after LLT, (e) Sn-0.7Cu-5Bi before LLT, (f) $\mathrm{Sn}-0.7 \mathrm{Cu}-5 \mathrm{Bi}$ after LLT.

Sn- $0.7 \mathrm{Cu}$ alloy has light regions of $\beta$-Sn grains and dark regions of eutectic colonies containing $\mathrm{Cu}_{6} \mathrm{Sn}_{5}$ intermetallic compounds (IMCs). From Figs. 3a,b, we can see that, although the two samples were cooled down from the same temperature, the microstructure became finer when the sample solidified from the melt experienced the LLT (sample B). The similar refining effect can be observed from Figs. 3c-f.
It can be speculated that the $\mathrm{Sn}-0.7 \mathrm{Cu}-x \mathrm{Bi}$ melt that did not undergo the LLT has lots of relative big-size clusters, which can easily reach the critical nucleation radius through fluctuations in structure and energy to nucleate under a low undercooling. Up to the LLT temperature, the big-size clusters absorb enough energy to disintegrate into smaller ones or break up so as to become absolutely disordered and homoge- 
Table 2. Wettability testing results of $\mathrm{Sn}-0.7 \mathrm{Cu}-x \mathrm{Bi}$ alloys

\begin{tabular}{llcccc}
\hline \multirow{2}{*}{ Alloy } & Melt status & Spreading area $\left(\mathrm{mm}^{2}\right)$ & Change rate of area & Contact angle & Change rate of contact angle \\
\hline \multirow{2}{*}{$\mathrm{Sn}-0.7 \mathrm{Cu}$} & Sample A & 45.467 & $+9.90 \%$ & $33.008^{\circ}$ & $-3.74 \%$ \\
& Sample B & 49.969 & & $31.775^{\circ}$ & $-3.09 \%$ \\
\multirow{2}{*}{ Sn-0.7Cu-3Bi } & Sample A & 51.864 & $+3.00 \%$ & $30.967^{\circ}$ & $30.008^{\circ}$ \\
& Sample B & 53.420 & & $29.225^{\circ}$ & $-6.44 \%$ \\
\multirow{2}{*}{$\mathrm{Sn}-0.7 \mathrm{Cu}-5 \mathrm{Bi}$} & Sample A & 51.326 & $+4.33 \%$ & $27.342^{\circ}$ & \\
& Sample B & 53.546 & & & \\
\hline
\end{tabular}

neous. On this condition, the melt needs a greater under-cooling to nucleate. Furthermore, with a greater under-cooling degree, the density of critical size nucleus and the nucleating rate would be higher while the growth rate becomes slower due to lower atom diffusion rate. Analysis from the both points of nucleation and growth shows that the solidification structure would be finer when it is solidified from the melt experienced LLT.

\subsection{Wettability}

The results of the spreadability testing of the solders are shown in Table 2. Compared with that of sample A, the spreading area of sample B with different $\mathrm{Bi}$ content is larger, while the wetting angle of sample B is smaller (as seen in Table 2).

During the soldering process, the wetting interaction was dominated by three surface tensions: the surface tension of the substrate/flux $\gamma_{\mathrm{SF}}$, the surface tension of the substrate/liquid solder interfacial area $\gamma_{\mathrm{SL}}$, and the surface tension of the liquid solder/flux $\gamma_{\mathrm{LF}}$. The equilibrium contact angle $\theta_{\text {eq }}$ is defined by the Young-Dupre equation [29]:

$$
\cos \theta_{\mathrm{eq}}=\frac{\gamma_{\mathrm{SF}}-\gamma_{\mathrm{SL}}}{\gamma_{\mathrm{LF}}}
$$

where $\gamma_{\mathrm{SF}}$ is determined by the structures of the substrate and flux, so $\gamma_{\mathrm{SF}}$ may be regarded as constant. $\gamma_{\mathrm{SL}}$ and $\gamma_{\mathrm{LF}}$ are determined by the properties of the molten alloy. The melt which experienced LLT is more disordered and homogeneous than the melt unexperienced, so atoms in the former state are more active than the latter. Therefore, when sample B started to melt and spread with temperature increasing, it was easy to spread on the $\mathrm{Cu}$ substrate due to the higher atoms' activity. Also, $\gamma_{\mathrm{SL}}$ and $\gamma_{\mathrm{LF}}$, which prevent molten alloy from spreading on the $\mathrm{Cu}$ substrate, decrease as a result of increased atoms' activity. According to Eq. (1), the equilibrium contact angle then decreases, and the wettability is improved when the melt has experienced LLT.

\section{Summary and conclusions}

From the investigated results, the conclusions are drawn as follows:

1. The anomaly on the $\rho-T$ curves suggests that there exist two kinds of LLTs in the $\mathrm{Sn}-0.7 \mathrm{Cu}-x \mathrm{Bi}$ melt - irreversible in the first cycle heating and reversible in the subsequent cycles. The irreversible LLT can be attributed to the metastable to stable transition of SROs, and the reversible LLT is closely related to the tetrahedral SROs with the covalent characteristic.

2. The LLT results in a more disordered melt which has an obvious effect on solidification and wettability. Because of the homogeneous and smaller size clusters, the disordered melt needs a higher undercooling to nucleate, and a higher nucleation rate will be obtained. Also, greater under-cooling degree inhibits the crystal growth of the primary phase owing to low atom diffusion rate. Eventually, the LLT refines the solidification microstructures.

3. For the disordered melt after LLT, the surface tension of $\gamma_{\mathrm{SL}}$ and $\gamma_{\mathrm{LF}}$ decreases due to the higher atoms' activity; so the equilibrium contact angle decreases and the spreading area on the $\mathrm{Cu}$ substrate increases to improve the wettability of the $\mathrm{Sn}-0.7 \mathrm{Cu}-$ $-x \mathrm{Bi}$ solder.

\section{Acknowledgements}

This work was supported by the National Natural Science Foundation of China (No. 50571033), the Natural Science Foundation of Anhui Province (No. 070414178 and No. 070416234)

\section{References}

[1] Chiriac, H., Vinai, F., Tomut, M., Stantero, A., Ferarra, E.: J. Non-Cryst. Solids, 250-252, 1999, p. 709. doi:10.1016/S0022-3093(99)00165-9

[2] Bian, X. F., Wang, W. M.: Mater. Lett., 44, 2000, p. 54. doi:10.1016/S0167-577X(00)00011-2

[3] Yin, F. S., Sun, X. F., Li, J. G., Guan, H. R., Hu, Z. Q.: Scripta Mater., 48, 2003, p. 425. doi:10.1016/S1359-6462(02)00446-3 
[4] Vollet, D. R., Donatti, D. A., Ibanez Ruiz, A., de Castro, W. C.: J. Non-Cryst. Solids, 332, 2003, p. 73 . doi:10.1016/j.jnoncrysol.2003.09.003

[5] Gunaratne, L. M. W. K., Shanks, R. A., Amarasinghe, G.: Thermochim. Acta, 423, 2004, p. 127. doi:10.1016/j.tca.2004.05.003

[6] Qiu, D., Zhang, M. X., Taylor, J. A., Fu, H. M., Kelly, P. M.: Acta Mater., 55, 2007, p. 1863. doi:10.1016/j.actamat.2006.10.047

[7] Aasland, S., McMillan, P.: Nature, 369, 1994, p. 633. doi: $10.1038 / 369633 \mathrm{a} 0$

[8] Harrington, S., Zhang, R., Poole, P. H., Sciortino, F., Stanley, H. E.: Phys. Rev. Lett., 78, 1997, p. 2409. doi:10.1103/PhysRevLett. 78.2409

[9] McMillan, P.: Nature, 403, 2000, p. 151. doi: $10.1038 / 35003088$

[10] Poole, P. H., Grande, T., Angell, C. A., McMillan, P. F.: Science, 275, 1997, p. 322. doi:10.1126/science.275.5298.322

[11] Beye, M., Sorgenfrei, F., Schlotter, W. F., Wurth, W. Föhlisch, A.: PANS, 107, 2010, p. 16772. doi:10.1073/pnas.1006499107

[12] He, Y. Z., Li, H., Jiang, Y. Y., Li, X. Y., Bian, X. F.: Scientific Reports, 4, 2014, p. 3635. doi:10.1038/srep03635

[13] Zu, F. Q., Li, X. F., Ding, H. F., Ding, G. H.: Phase Transit., 79, 2006, p. 277. doi:10.1080/01411590600703137

[14] Li, X. F., Hu, C. M., Zu, F. Q.: Kovove Mater., 2, 2009, p. 109.

[15] Zu, F. Q., Shen, R. R., Xi, Y., Li, X. F., Ding, G. H., Liu, H. M.: J. Phys.: Condens. Matter, 18, 2006, p. 2817. doi:10.1088/0953-8984/18/10/007

[16] Zu, F. Q., Zhu, Z. G., Guo, L. J., Qin, X. B., Yang, H., Shan, W. J.: Phys. Rev. Lett., 89, 2002, p. 125505. doi:10.1103/PhysRevLett.89.125505
[17] Zu, F. Q., Li, X. F., Guo, L. J., Yang, H., Qin, X. B., Zhu, Z. G.: Phys. Lett. A, 324, 2004, p. 472. doi:10.1016/j.physleta.2004.03.014

[18] Zu, F. Q., Zhu, Z. G., Zhang, B., Feng, Y., Shui, J. P.: J. Phys.: Condens. Matter, 13, 2001, p. 11435. doi:10.1088/0953-8984/13/50/303

[19] Chen, J., Zu, F. Q., Li, X. F., Ding, G. H., Chen, H. S., Zhou, L.: Met. Mater. Int., 14, 2008, p. 569. doi:10.3365/met.mat.2008.10.569

[20] Kang, S. K., Sarkhel, A. K.: J. Electron. Mater., 23, 1994, p. 701. doi:10.1007/BF02651362

[21] Suganuma, K.: Curr. Opin. Solid. St. M., 5, 2001, p. 55. doi:10.1016/S1359-0286(00)00036-X

[22] Richter, H., Breitling, G.: Z. Metalkd., 61, 1970, p. 628.

[23] Mitus, A. C., Patashinkii, A. Z., Shumilo, B. I.: Phys. Lett. A, 113, 1985, p. 41. doi:10.1016/0375-9601(85)90602-4

[24] Zhao, N., Pan, X. M., Ma, H. T., Wang, L.: Acta Metall. Sin., 44, 2008, p. 467.

[25] Popel, P. S., Chikova, O. A., Matveev, V. M.: High Temp. Mater. Proc., 14, 1995, p. 219. doi:10.1515/HTMP.1995.14.4.219

[26] Itami, T., Munejiri, S., Masaki, T., Aoki, H., Ishii, Y., Kamiyama, T., Senda, Y., Shimojo, F., Hoshino, K.: Phys. Rev. B, 67, 2003, p. 064201. doi:10.1103/PhysRevB.67.064201

[27] Qin, J. Y., Bian, X. F., Wang, W. M.: Acta Metall. Sin., 47, 1998, p. 438. doi:10.7498/aps.47.438

[28] Shen, J., Liu, Y., Gao, H.: J. Univ. Sci. Technol. Beijing, 13, 2006, p. 333. doi:10.1016/S1005-8850(06)60069-8

[29] Adamson, A. W.: Physical Chemistry of Surfaces. 5th Edition. New York, Wiley 1990. 